\title{
Inhibition of Rac1 activity induces G1/S phase arrest through the GSK3/cyclin D1 pathway in human cancer cells
}

\author{
LINNA LIU $^{1 *}$, HONGMEI ZHANG $^{2 *}$, LEI SHI ${ }^{1}$, WENJUAN ZHANG ${ }^{1}$, JUANLI YUAN $^{1}$, \\ XIANG CHEN ${ }^{3}$, JUANJUAN LIU ${ }^{4}$, YAN ZHANG ${ }^{1}$ and ZHIPENG WANG ${ }^{4}$ \\ ${ }^{1}$ Department of Pharmaceutics, Tangdu Hospital, Fourth Military Medical University, Xi'an, Shaanxi 710038; \\ ${ }^{2}$ Department of Clinical Oncology, Xijing Hospital, Fourth Military Medical University, Xi'an, Shaanxi 710032; \\ ${ }^{3}$ Department of Orthopedics, Tangdu Hospital, Fourth Military Medical University, Xi'an, Shaanxi 710038; \\ ${ }^{4}$ Department of Pharmacology, School of Pharmacy, Fourth Military Medical University, Xi'an, Shaanxi 710032, P.R. China
}

Received March 7, 2014; Accepted April 16, 2014

DOI: $10.3892 / o r .2014 .3388$

\begin{abstract}
Rac1 has been shown to regulate the cell cycle in cancer cells. Yet, the related mechanism remains unclear. Thus, the present study aimed to investigate the mechanism involved in the regulation of G1/S phase transition by Rac1 in cancer cells. Inhibition of Rac1 by inhibitor NSC 23766 induced G1/S phase arrest and inhibited the proliferation of A431, SW480 and U2-OS cells. Suppression of GSK3 by shRNA partially rescued G1/S phase arrest and inhibition of proliferation. Incubation of cells with NSC23766 reduced p-AKT and inactivated p-GSK $3 \alpha$ and p-GSK3 $\beta$, increased p-cyclin D1 expression and decreased the level of cyclin D1 protein. Consequently, cyclin D1 targeting transcriptional factor E2F1 expression, which promotes G1 to S phase transition, was also reduced. In contrast, constitutive active Rac1 resulted in increased p-AKT and inactivated p-GSK3 $\alpha$ and p-GSK3 $\beta$, decreased p-cyclin D1 expression and enhanced levels of cyclin D1 and E2F1 expression. Moreover, suppression of GSK3 did not alter p-AKT or Rac1 activity, but decreased p-cyclin D1 and increased total cyclin D1 protein. However, neither Rac1 nor GSK3 inhibition altered cyclin D1 at the RNA level. Moreover, after inhibition of Racl or GSK3 following proteasome inhibitor MG132 treatment, cyclin D1 expression at the protein level remained constant, indicating that Rac1 and GSK3 may regulate cyclin D1 turnover through phosphorylation and degradation. Therefore, our findings
\end{abstract}

Correspondence to: Dr Zhipeng Wang, Department of Pharmacology, School of Pharmacy, Fourth Military Medical University, Xi'an, Shaanxi 710032, P.R. China

E-mail: zhipengw@fmmu.edu.cn

Dr Yan Zhang, Department of Pharmaceutics, Tangdu Hospital, Fourth Military Medical University, Xi'an, Shaanxi 710038, P.R. China E-mail: tangdugcp@126.com

${ }^{*}$ Contributed equally

Key words: Rac1, cell cycle, GSK, cyclin, cancer suggest that inhibition of Rac1 induces cell cycle G1/S arrest in cancer cells by regulation of the GSK3/cyclin D1 pathway.

\section{Introduction}

Rac1 is a member of the small RhoGTPase family, that is activated by binding to GTP, and inactivated by binding to GDP. It regulates a wide range of cellular properties, such as proliferation, differentiation, apoptosis and migration (1). It is also crucial in regulation of the cell cycle in human cancer cells (2). However, the mechanism is largely unknown.

G1 to $\mathrm{S}$ phase transition is a pivotal step in the cell cycle and plays a crucial role in various biological processes, such as cell proliferation, terminal differentiation, senescence or cell death (3). Cyclin D1 is a key molecule that is required for $\mathrm{S}$ phase entry. Overexpression of cyclin D1 accelerates G1/S transition (4). On the other hand, inhibition of cyclin D1 induces cell cycle arrest in the G1 phase. In association with cyclin D1, cyclin-dependent kinases (CDKs) CDK4 and CDK6 phosphorylate their substrates, such as retinoblastoma protein (pRb), allowing the release of E2F transcription factors that activate G1/S-phase gene expression (5). The level of cyclin D protein is reduced through downregulation of protein expression or phosphorylation-dependent degradation due to ubiquitination and proteasome-mediated degradation (6).

Glycogen synthase kinase-3 (GSK3) is a critical downstream element of the PI3K/AKT pathway. Therefore, its activity can be inhibited by AKT-mediated phosphorylation at Ser 21 of GSK $3 \alpha$ and Ser9 of GSK $3 \beta(7,8)$. GSK $3 \beta$ is reported to phosphorylate cyclin D1 at Thr286. AKT positively regulates G1/S cell cycle progression through inactivation of GSK3 $\beta$, resulting in increased cyclin D1. As a target of cyclin D1, E2F1 promotes cell cycle by binding to different genes, such as myc and TK $(9,10)$.

Rac1 has been shown to regulate the cell cycle by regulation of cyclin D1 (11). However, the intermediary molecules are unclear. Joyce et al (12) reported that Rac1 regulates cyclin D1 transcription through $\mathrm{NF}-\kappa \mathrm{B}$-dependent signaling in NIH3T3 cells. However, our previous study found that $\mathrm{NF}-\kappa \mathrm{B}$ was not altered in Rac1-depleted keratinocytes compared to wild-type keratinocytes in vivo and in vitro (13). 
Therfore, the downstream pathway of Rac1 involved in the regulation of G1/S transition through cyclin D1 seems to be variable in different cell types.

In the present study, we aimed to investigate the mechanism involved in the regulation of G1/S transition by Racl in cancer cells. We found that inhibition of Rac1 activity induced G1/S phase arrest through the GSK3/cyclin D1 pathway.

\section{Materials and methods}

Cell culture. A431 human epithelial carcinoma cells, SW480 human colon cancer cells and U2-OS human osteosarcoma cells were grown in Dulbecco's modified Eagle's medium (DMEM) (Gibco) supplemented with $10 \%$ fetal bovine serum (FBS), $100 \mathrm{U} / \mathrm{ml}$ penicillin and $0.1 \mathrm{mg} / \mathrm{ml}$ streptomycin at $37^{\circ} \mathrm{C}$ in $5 \% \mathrm{CO}_{2}$. Rac1 inhibitor NSC23766 (Calbiochem) and GSK3 inhibitor lithium (Sigma) in PBS at final concentrations of $100 \mu \mathrm{M}$ and $100 \mathrm{mM}$ were used.

Plasmid constructs and gene transfer. shRNA against GSK3 and the GSK3-overexpressing plasmid were purchased from Shanghai GenePharma Co., Ltd (Shanghai, China). High cycling Rac1 plasmid was a gift from Professor Cord Brakebusch at the University of Copenhagen, Denmark. A431, SW480 and U2-OS cells were transfected using MirusTransIT transfection reagents according to the manufacturer's instructions, and selected by G418 for setting up stable transfection.

MTT assay. A431, SW480 and U2-OS cells were plated in quintuplicate in 96 -well plates $\left(5 \times 10^{3} /\right.$ well). At $24 \mathrm{~h}$ after incubation, NSC23766 or $\mathrm{LiCl}$ was added to a final concentration of $100 \mu \mathrm{M}$ or $100 \mathrm{mM}$, respectively, for 1,2 or 3 days. Next, $20 \mu 1$ of $5 \mathrm{mg} / \mathrm{ml}$ MTT (Sigma, St. Louis, MO, USA) was added to each well for $4 \mathrm{~h}$ at $37^{\circ} \mathrm{C}$. Dimethylsulfoxide (DMSO) $(150 \mu \mathrm{l})$ was added to dissolve the crystals, and absorbance was measured with an enzyme-linked immunosorbent assay reader (Bio-Rad Laboratories, Hercules, CA, USA), using a measurement wavelength of $570 \mathrm{~nm}$.

Cell cycle analysis. A431, SW480 and U2-OS cells were seeded in 6-well plates at $3 \times 10^{5}$ cells/well, and incubated with NSC23766 or LiCl added to a final concentration of $100 \mu \mathrm{M}$ or $100 \mathrm{mM}$, respectively, for $24 \mathrm{~h}$. Cells were harvested by centrifugation and fixed with $75 \%$ ethanol. Fixed cells were incubated with propidium iodide for at least $30 \mathrm{~min}$. The DNA content of the cells was measured on a FACScan cytometer (Becton-Dickinson).

Western blot analysis. Western blot analysis was performed as previously described (14). Cell lysates were prepared from cell monolayers incubated in RIPA buffer $[50 \mathrm{mM}$ Tris- $\mathrm{HCl}$ (pH 7.4), $150 \mathrm{mM} \mathrm{NaCl}, 2 \mathrm{mM}$ EDTA, $1 \mathrm{mM}$ sodium orthovanadate, $1 \%$ Nonidet $\mathrm{P}-40,1 \%$ sodium deoxycholate, $0.1 \%$ sodium dodecyl sulfate (SDS), $2 \mathrm{mM}$ phenylmethylsulfonyl fluoride (PMSF)] and protease inhibitor cocktail. Total cellular protein samples of $50 \mu \mathrm{g}$ were resolved by SDS-PAGE. Blots were probed with anti-Rac1, p-AKT (Ser473), GSK3 $\alpha$, p-GSK3 $\alpha$ (Ser21), GSK3 $\beta$, p-GSK3 $\beta$ (Ser9), cyclin D1, p-cyclin D1 (Thr286), CDK4, CDK6 and E2F1 antibodies purchased from Cell Signaling Technology. The same antibodies were used for immunofluoresent staining. Anti-tubulin (Abcam) was used as the loading control. Secondary antibodies were goat antirabbit or goat anti-mouse coupled to horseradish peroxidase. Development was carried out with enhanced chemiluminescence reagents (Millipore, Billerica, MA, USA), and signals were detected by a chemiluminescence detection system (Clinx Science Instruments Co., Ltd., Shanghai, China).

Reverse transcription PCR (RT-PCR). Total RNA was isolated from cells using the TRIzol reagent (Sigma) according to the manufacturer's protocol. Reverse transcription was performed using the RT-PCR kit (BD Biosciences) following the manufacturer's protocol. cDNA was then amplified. The reaction condition was first heated at $95^{\circ} \mathrm{C}$ for $5 \mathrm{~min}$, then 30 cycles at $95^{\circ} \mathrm{C}$ for $1 \mathrm{~min}$, followed at $55^{\circ} \mathrm{C}$ for $1 \mathrm{~min}$ and $72^{\circ} \mathrm{C}$ for $1 \mathrm{~min}$, then $72^{\circ} \mathrm{C}$ for $10 \mathrm{~min}$. Primers were: cyclin D1, 5'-CACA CGGACTACAGGGGAGT-3' (forward) and 5'-CACAGGA GCTGGTGTTCCAT-3' (reverse); E2F1, 5'-ATGTTTTCCTG TGCCCTGAG-3' (forward) and 5'-ATCTGTGGTGAGGGA TGAGG-3' (reverse); GAPDH, 5'-GAGTCCACTGGCGTC TTC-3' (forward) and 5'-GGGGTGCTAAGCAGTTGGT-3' (reverse).

Statistical analysis. All data are presented as means \pm standard deviation (SD). Statistical significance was determined by the Student's t-test. P-values $<0.01$ were considered significant. Analyses were performed using SPSS 11.0.

\section{Results}

Racl activity is crucial for cancer cell proliferation. The role of Rac1 activity was assessed using Rac1 inhibitor NSC23766 that has been confirmed to inhibit Rac1 activity by interfering with the interaction between GEF and Rac1 (15), consequently inhibiting activation. MTT assay was performed to test cell proliferation. Fig. 1 shows that NSC23766 at the concentration of $100 \mu \mathrm{M}$ inhibited proliferation in A431 skin cancer cells, SW480 colon cancer cells and U2-OS osteosarcoma cells $(\mathrm{P}<0.01)$. However, suppression of GSK3 partially rescued this inhibition in all three cancer cell lines.

Inhibition of Racl induces G1/S phase arrest. The cell cycle is a crucial effector of proliferation. Using flow cytometry, we found that inhibition of Rac1 activation by NSC23766 markedly induced cell cycle arrest in the G1 phase in the A431, SW480 and U2-OS cells ( $\mathrm{P}<0.01$; Fig. 2). Suppression of GSK3 partially rescued this effect in all three cancer cell lines.

Inhibition of Racl suppresses cyclin D1 through GSK3. In A431 cells, following incubation of NSC23766, phosphorylation of AKT at ser473 was decreased. Consequently, phosphorylation of both GSK $3 \alpha$ and GSK3 $\beta$ was reduced as well. Total expression of GSK $3 \alpha$ and GSK $3 \beta$ was slightly increased after incubation of NSC23766. Higher levels of p-cyclin D1 and a lower level of total cyclin D1 were observed in the Rac1inhibited cells, while CDK4 and CDK6 expression was not altered. The transcription factor E2F1, a target of cyclin D1, was repressed following inhibition of Racl activation. The changes in the above proteins were similar in the SW480 and U2-OS cells (Fig. 3A). In contrast, constitutive active Rac1 

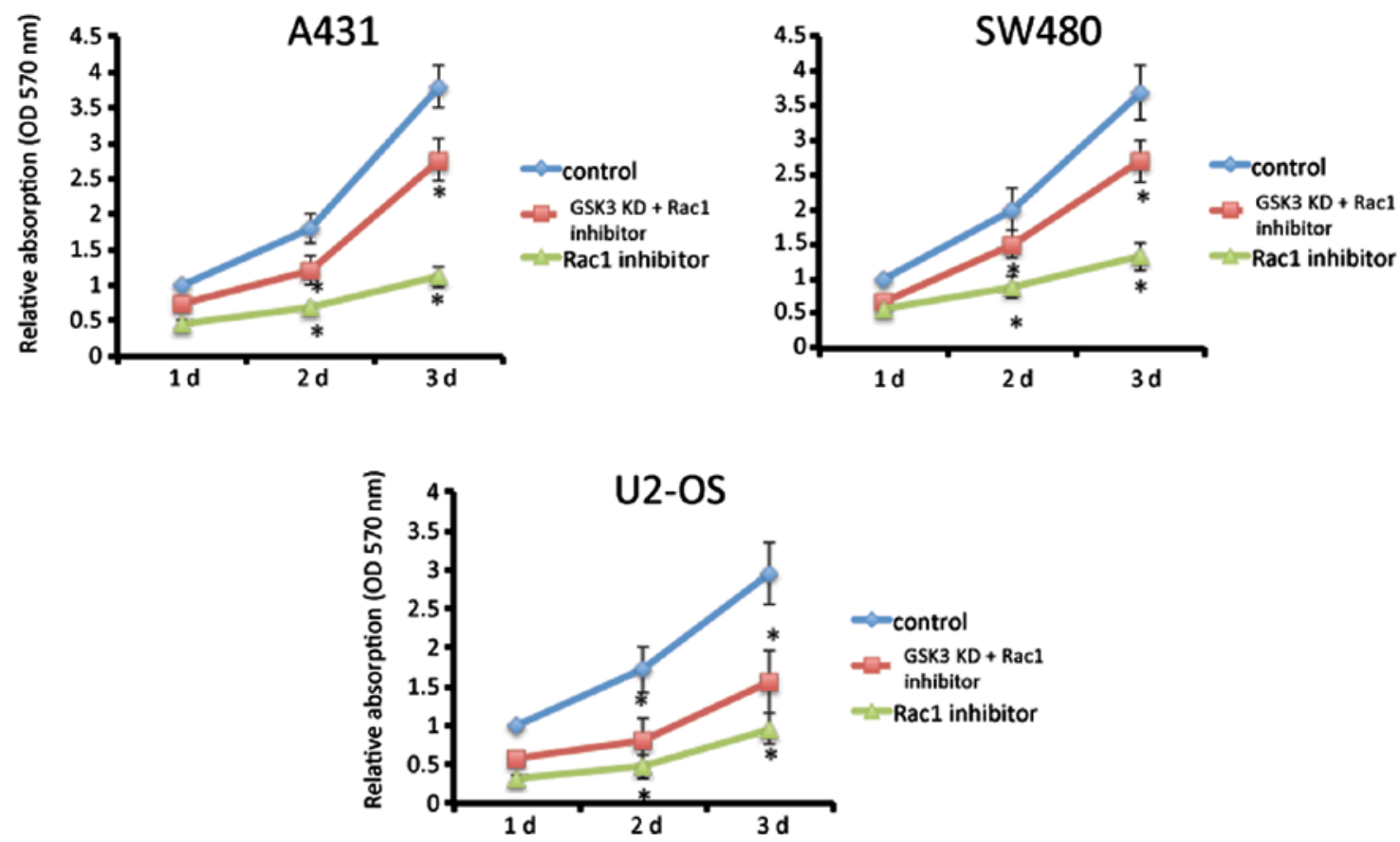

Figure 1. Inhibition of cancer cell proliferation by Rac1 inhibitor treatment. Control A431, SW480 and U2-OS cells, as well as GSK3-knockdown cell lines were treated with Rac1 inhibitor NSC23766 for 1, 2 and 3 days. Survival probability was determined by MTT assay. Data are means with standard deviation $(\mathrm{n}=8)$. Data analysis was performed with the Student's t-test. ${ }^{*} \mathrm{P}<0.01$, compared to the control.

A

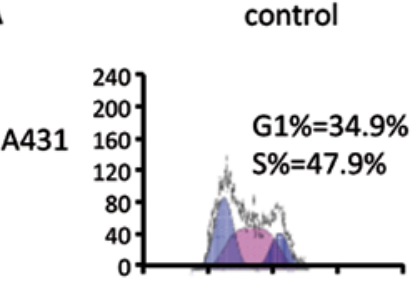

U2-OS



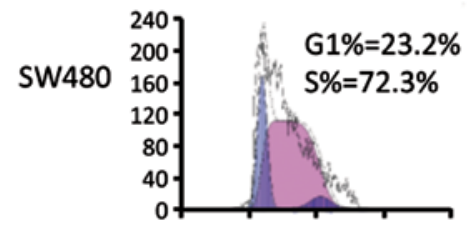

Rac1 inhibitor
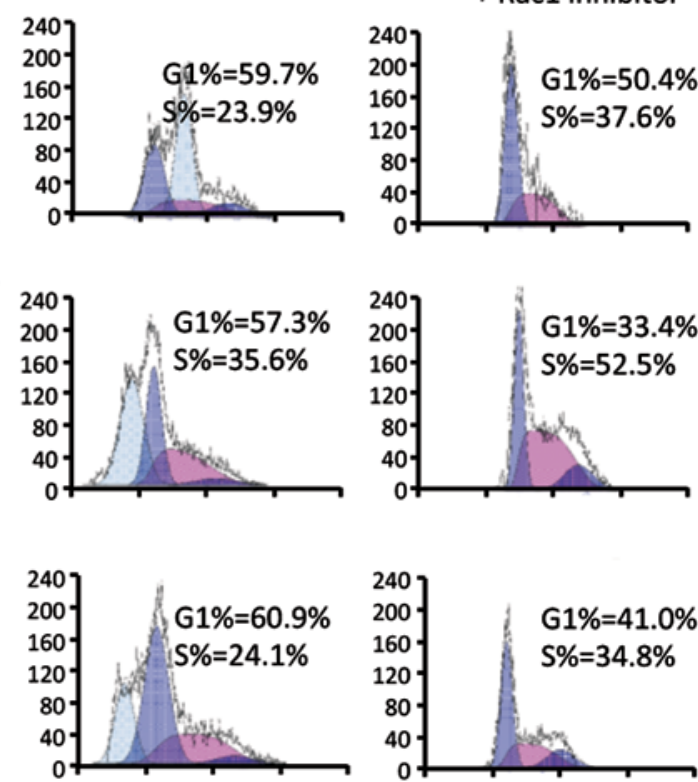

B
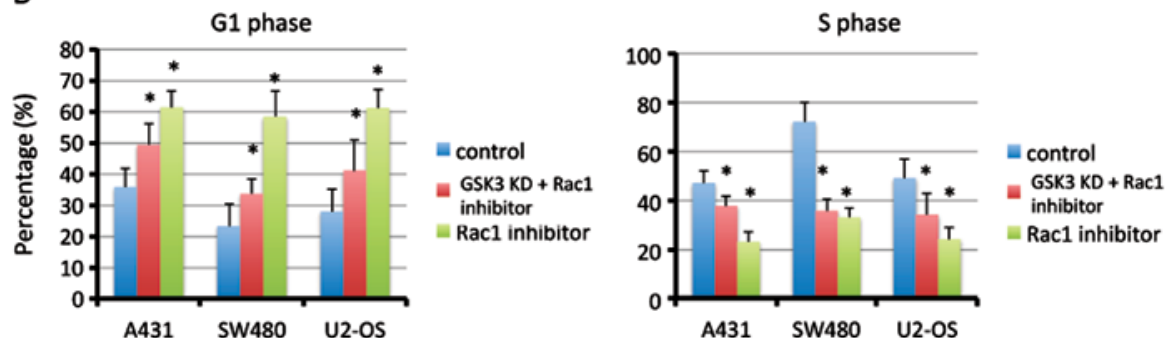

Figure 2. Flow cytometric analysis of the cell cycle of cancer cells. (A) Control A431, SW480 and U2-OS cells or GSK3-knockdown (GSK3-KD) cell lines were treated with Rac1 inhibitor NSC23766 for $24 \mathrm{~h}$. Cells were harvested, and cell cycle analysis was performed as described in Materials and methods. Shown are the percentages of cells in the G1 and S phase. (B) Quantification of cell cycle analysis $(n=3)$. Data analysis was performed with the Student's t-test. ${ }^{*} \mathrm{P}<0.01$, compared to the control. 
A

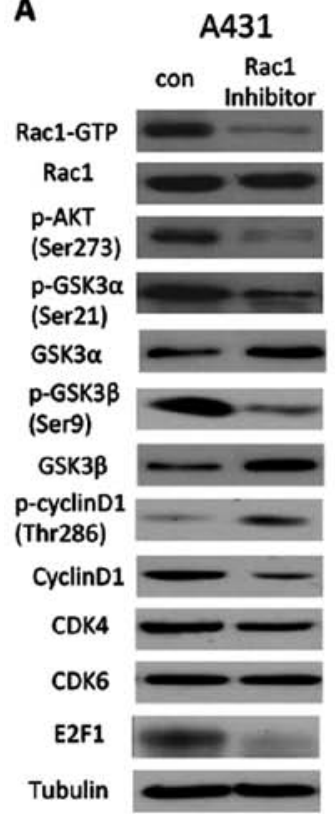

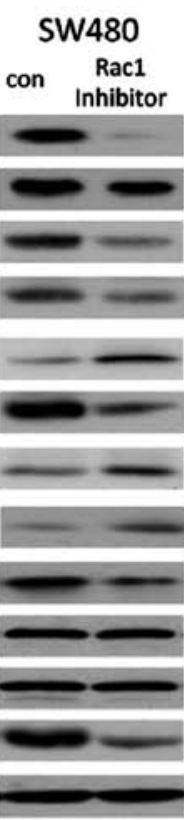

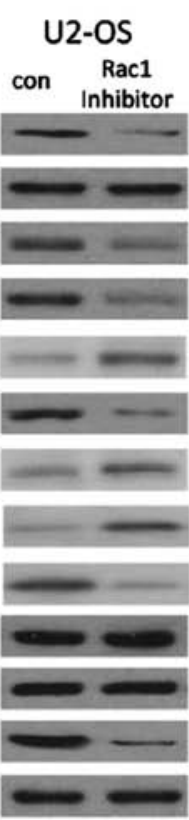

B

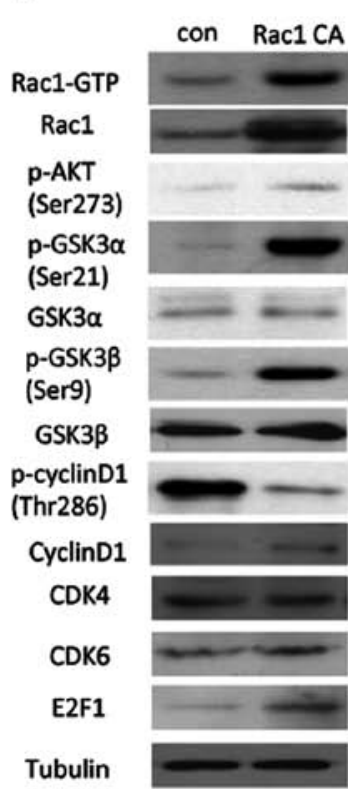

C

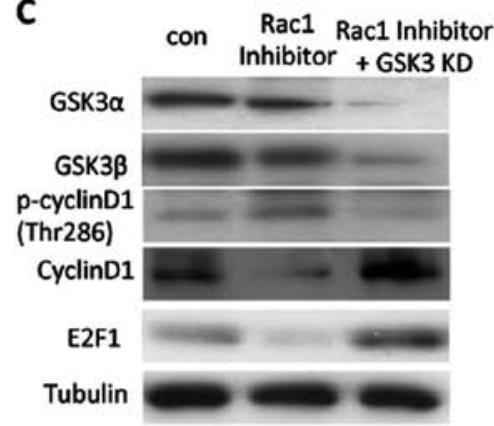

Figure 3. Effect of Rac1 on GSK3/cyclin D1 signaling. (A) A431, SW480 and U2-OS cells were treated with NSC23766 (Rac1 inhibitor) for $24 \mathrm{~h}$ and protein lysates were prepared. Western blotting was used to detect indicated protein expression. Pull down assay was used to test Rac1 activity (Rac1-GTP). (B) SW480 cells were transfected with control plasmid (con) or high cycling Rac1 plasmid (Rac1 CA). Western blotting was used to detect indicated protein expression. (C) SW480 cells were transfected with shRNA against GSK3 (GSK3 KD) or control plasmid (con). Cells were treated with NSC23766 (Rac1 inhibitor) for $24 \mathrm{~h}$. Western blotting was used to detect indicated protein expression.

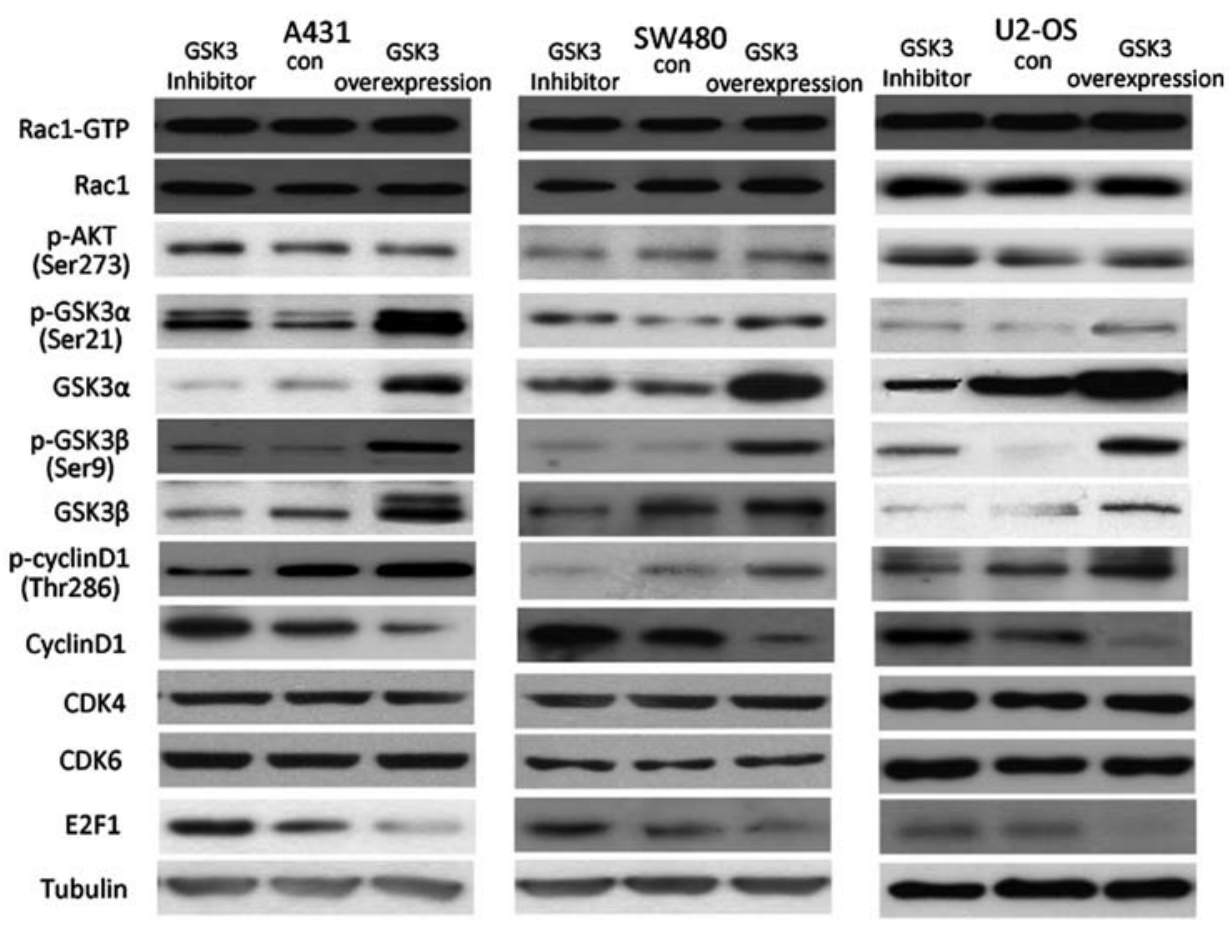

Figure 4. Effect of GSK3 on cyclin D1 signaling. Control (con), LiCl-treated (GSK inhibitor) or GSK3 overexpression cells (A431, SW480 and U2-OS) were cultured. Protein lysates were prepared. Western blotting was used to detect indicated protein expression. Pull down assay was used to test Rac1 activity (Rac1-GTP).

in SW480 cells induced a higher level of p-AKT, p-GSK3 $\alpha$ and p-GSK3 $\beta$. A lower level of p-cyclin D1 and higher levels of cyclin D1 and E2F1 were observed in the Rac1-activated cells (Fig. 3B). Moreover, suppression of GSK3 reduced p-cyclin D1, increased total levels of cyclin D1 and E2F1, even in the presence of the Rac1 inhibitor (Fig. 3C).
Inhibition of GSK3 suppresses cyclin D1 and E2F1. In the A431 cells, following incubation with $\mathrm{LiCl}$, a GSK3 inhibitor, phosphorylation of both GSK $3 \alpha$ and GSK $3 \beta$ was elevated, while total expression of GSK $3 \alpha$ and GSK3 $\beta$ was reduced. Neither Rac1 activity nor AKT phosphorylation was altered when GSK3 activity was inhibited, indicating that GSK3 functions down- 

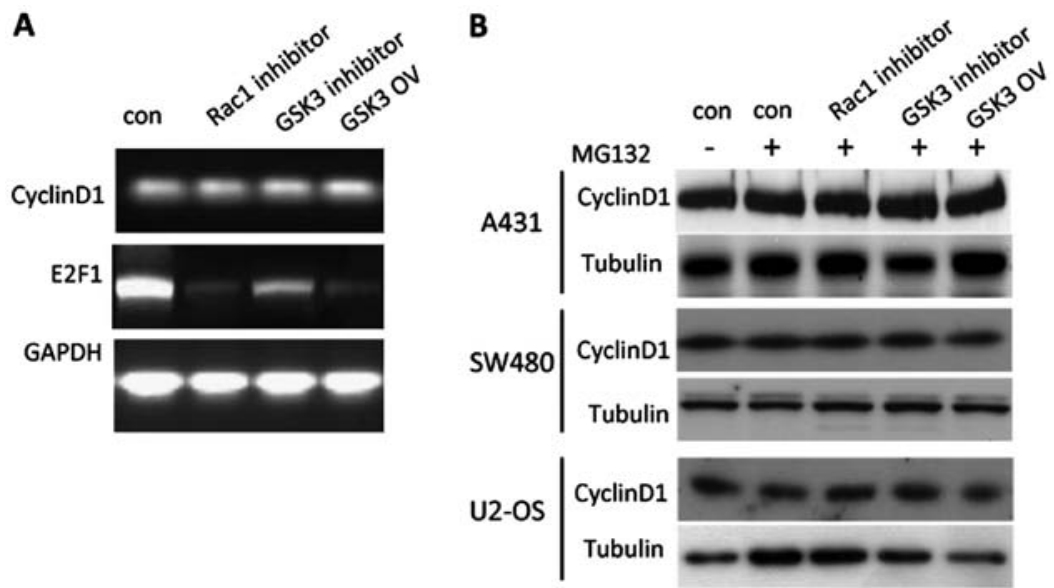

Figure 5. Effects of Rac1 and GSK3 on cyclin D1 at the RNA and protein levels. (A) NSC23766 (Rac1 inhibitor) or LiCl-treated (GSK3 inhibitor) A431 cells and GSK3 overexpressing (GSK3 OV) A431 cells were cultured. Total RNA was extracted. Expression levels of cyclin D1 and E2F1 RNA were evaluated by RT-PCR. (B) NSC23766 (Rac1 inhibitor) or LiCl-treated (GSK3 inhibitor) cells and GSK3-overexpressing (GSK3 OV) cells were cultured with or without proteasome inhibitor MG132. Expression of cyclin D1 was tested by western blot analysis.

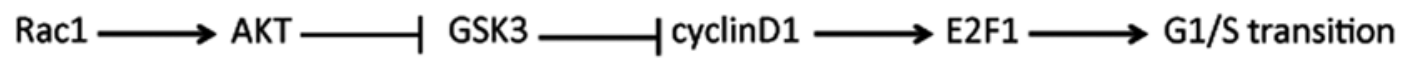

Figure 6. Rac1 regulates G1 to S phase transition through the GSK3/cyclin D1 pathway.

stream of Rac1 and AKT. Followed by decrease in the GSK3 level following incubation with $\mathrm{LiCl}$, cyclin $\mathrm{D} 1$ phosphorylation was reduced and total cyclin D1 was increased, possibly resulting in a higher level of E2F1. Furthermore, overexpression of GSK3 in the A431 cells further increased p-cyclin D1 and decreased the total amount of cyclin D1 and E2F1 protein, suggesting that GSK3 is a molecule that regulates cyclin D1 phosphorylation and expression downstream of Racl and AKT. Similar results were observed in the SW480 and U2-OS cells (Fig. 4).

Notably, neither inhibition of Rac1 and GSK3 activity nor elevated GSK3 expression altered cyclin D1 expression at the RNA level. Moreover, expression of cyclin D1 at the protein level remained constant in the presence of the proteasome inhibitor MG132 at the concentration of $50 \mu \mathrm{M}$ (Fig. 5). These results indicate that Rac1 and GSK3 may change cyclin D1 protein expression at the post-transcription level. E2F1 expression was markedly reduced at the RNA level when Racl or GSK3 was inactivated, suggesting that Rac1 and GSK3 regulate E2F1 expression at the transcription level.

\section{Discussion}

Rac1 is either overexpressed or overactivated in many cancer types, such as colon, testicular, gastric, breast, oral and skin squamous cell carcinoma (1). Rac1 has been demonstrated to be crucial for tumor formation by control of transformation, proliferation and survival of tumor cells. We inhibited Rac1 activity in A341 skin cancer cells, SW480 colon cancer cells and U2-OS osteosarcoma cells, and proliferation of the three cell lines was significantly reduced, indicating the indispensible role of Rac1 in cancer cell proliferation. However, suppression of GSK3 partially rescued this inhibition of proliferation, suggesting that Rac1 regulates cell proliferation via GSK3.
Cell cycle progression is the process of cell division, which decides the speed of cell proliferation (16). In early G1, cyclin D1 associates with CDK4 and CDK6 to form active cyclin D/CDK4/CDK6 complexes (17). This complex is responsible for targeting nuclear transcription factors. In the present study, inhibition of Rac1 or GSK3 activity induced cell cycle arrest in the G1 phase in all three cancer cell lines. This cell cycle arrest was partially rescued by suppression of GSK3, suggesting that Rac1 regulates the cell cycle through GSK3.

GSK3 functions to phosphorylate cyclin D1 at Thr286, subsequently inducing its proteasomal degradation, thereby triggering cyclin D1 turnover (18). Inhibition of Rac1 activity reduced the phosphorylation of AKT, consistent with previous results that phosphorylation of AKT was decreased in Rac1depleted epidermis treated by TPA (15). In contrast, constitutive active Rac1 induced higher levels of p-AKT, p-GSK3 $\alpha$ and p-GSK3 $\beta$, a lower level of p-cyclin D1, as well as a higher level of cyclin D1, indicating that the GSK3/cyclin D1 pathway is regulated by Rac1.

GSK3 activity can be phosphorylated and inhibited by the PI3K/AKT pathway (7). GSK3 $\alpha$ and GSK3 $\beta$ phosphorylation was reduced when Racl was inhibited, possibly due to the inactivation of AKT, resulting in the increase in the amount of GSK $3 \alpha$ and GSK $3 \beta$ protein. GSK3 is known to phosphorylate and degrade cyclin D1. Suppression of GSK3 reduced p-cyclin D1 and increased the total level of cyclin D1 (Fig. 3C). Moreover, the level of p-cyclin D1 was increased, possibly due to the higher protein level of GSK3 in the Rac1-inhibited cancer cells, correlating with a lower cyclin D1 protein level, possibly due to increased cyclin D1 degradation after phosphorylation. To confirm this hypothesis, we performed RT-PCR to assess the expression of cyclin D1 at the RNA level in the Rac1-inhibited cancer cells. Results showed that cyclin D1 
expression at the RNA level remained constant in the Rac1inhibited, GSK3-inhibited and overexpressing cells. We next inhibited the proteasome to inhibit ubiquitination and degradation of cyclin D1. Expression of cyclin D1 at the protein level remained unchanged in the Rac1-inhibited, GSK3-inhibited and overexpressing cells. These results suggest that Rac1 and GSK3 regulate cyclin D1 expression at the post-transcription level, possibly by the effect of ubiquitination and degradation.

E2F1, known as a downstream target of cyclin D1 and a member of the E2F family that induces G1 phase entry to $\mathrm{S}$ phase, is a potent stimulator of cell cycle entry $(19,20)$. It binds to specific DNA sequences and regulates transcription of E2F target genes. E2F1 was suppressed following inhibition of Rac1 activity or GSK3 activity, but was overexpressed by constitutive active Rac1 or suppression of GSK3, followed by increased or decreased cyclin D1.

In conclusion, in the cancer cell lines, inhibition of Rac1 reduced AKT phosphorylation, thus inhibiting GSK3 phosphorylation, resulting in an elevated level of GSK3. This subsequently induced a higher level of p-cyclin D1, which induced degradation of cyclin D1, leading to suppression of E2F1 resulting in induction of G1/S phase arrest (Fig. 6).

\section{Acknowledgements}

The present study was sponsored by the National Natural Science Foundation of China (nos. 81071689 and 81202119) and the Key Foundation of Shaanxi Province for International Communication (2013KW30-01).

\section{References}

1. Karlsson R, Pedersen ED, Wang Z and Brakebusch $\mathrm{C}$ : RhoGTPases function in tumor. Biochim Biophys Acta 1796 : 91-98, 2009.

2. Qiu RG, Chen J, McCormick F and Symons M: A role for Rho in Ras transformation. Proc Natl Acad Sci USA 92: 11781-11785, 1995.

3. Richard-Parpaillon L, Cosgrove RA, Devine C, Vernon AE and Philpott A: G1/S phase cyclin-dependent kinase overexpression perturbs early development and delays tissue-specific differentiation in Xenopus. Development 131: 2577-2586, 2004.

4. Quelle DE, Ashmun RA, Shurtleff SA, Kato JY, Bar-Sagi D, Roussel MF and Sherr CJ: Overexpression of mouse D-type cyclins accelerates G1 phase in rodent fibroblasts. Genes Dev 1559-1571, 1993.

5. Nevins JR: E2F, a link between the Rb tumor suppressor protein and viral oncoproteins. Science 258: 424-429, 1992.
6. Hsieh TC, Yang CJ, Lin CY, Lee YS and Wu JM: Control of stability of cyclin D1 by quinone reductase 2 in CWR22Rv1 prostate cancer cells. Carcinogenesis 33: 670-677, 2012.

7. Rahmani M, Aust MM, Attkisson E, Williams DC Jr, FerreiraGonzalez A and Grant S: Dual inhibition of Bcl-2 and Bcl-xL strikingly enhances PI3K inhibition-induced apoptosis in human myeloid leukemia cells through a GSK3- and Bim-dependent mechanism. Cancer Res 73: 1340-1351, 2013.

8. Moore SF, van den Bosch MT, Hunter RW, Sakamoto K, Poole AW and Hers I: Dual regulation of glycogen synthase kinase $3(\mathrm{GSK} 3) \alpha / \beta$ by protein kinase $\mathrm{C}(\mathrm{PKC}) \alpha$ and Akt promotes thrombin-mediated integrin $\alpha \operatorname{IIb} \beta_{3}$ activation and granule secretion in platelets. J Biol Chem 288: 3918-3928, 2013.

9. Rhee K, Ma T and Thompson EA: The macromolecular state of the transcription factor $\mathrm{E} 2 \mathrm{~F}$ and glucocorticoid regulation of c-myc transcription. J Biol Chem 269: 17035-17042, 1994.

10. Sahin F and Sladek TL: E2F-1 has dual roles depending on the cell cycle. Int J Biol Sci 6: 116-128, 2010.

11. Olson MF, Ashworth A and Hall A: An essential role for Rho, Rac, and Cdc42 GTPases in cell cycle progression through G1. Science 269: 1270-1272, 1995.

12. Joyce D, Bouzahzah B, Fu M, Albanese C, D'Amico M, Steer J, Klein JU, Lee RJ, Segall JE, Westwick JK, Der CJ and Pestell RG: Integration of Rac-dependent regulation of cyclin D1 transcription through a nuclear factor- $\mathrm{KB}$-dependent pathway. $\mathrm{J}$ Biol Chem 274: 25245-25249, 1999.

13. Peterson E, Wang Z, Stanley A, Peyrollier K, Quondamatteo F and Brakebusch C: Racl in keratinocytes regulates crosstalk to immune cells by Arp2/3 control of STAT1. J Cell Sci 125: 5379-5390, 2012.

14. Wang Z, Zhu S, Shen Min, Liu J, Wang M, Li C, Wang Y and Mei Q: STAT3 is involved in esophageal carcinogenesis through regulation of Oct-1. Carcinogenesis 34: 678-688, 2013.

15. Wang Z, Pedersen E, Basse A, Lefever T, Karine P, Kapoor S, Mei Q, Karlsson R and Brakebusch C: Racl is crucial for Ras-dependent skin tumor formation by controlling Pak1Mek-Erk hyperactivation and hyperproliferation in vivo. Oncogene 29: 3362-3373, 2010.

16. Wang D, Sun SQ, Yu YH, Wu WZ, Yang SL and Tan JM: Suppression of SCIN inhibits human prostate cancer cell proliferation and induces G0/G1 phase arrest. Int J Oncol 44: 161-166, 2014.

17. Chiron D, Martin P, Di Liberto M, Huang X, Ely S, Lannutti BJ, Leonard JP, Mason CE and Chen-Kiang S: Induction of prolonged early $\mathrm{G} 1$ arrest by CDK4/CDK6 inhibition reprograms lymphoma cells for durable PI3K $\delta$ inhibition through PIK3IP1. Cell Cycle 12: 1892-1900, 2013.

18. Diehl JA, Cheng M, Roussel MF and Sherr CJ: Glycogen synthase kinase-3 $\beta$ regulates cyclin D1 proteolysis and subcellular localization. Genes Dev 12: 3499-3511, 1998.

19. Peng $\mathbf{J}$ and Jordan VC: Expression of estrogen receptor alpha with a Tet-off adenoviral system induces G0/G1 cell cycle arrest in SKBr3 breast cancer cells. Int J Oncol 36: 451-458, 2010.

20. Subtil-Rodríguez A, Vázquez-Chávez E, Ceballos-Chávez M, Rodríguez-Paredes M, Martín-Subero JI, Esteller $M$ and Reyes JC: The chromatin remodeller CHD8 is required for E2F-dependent transcription activation of S-phase genes. Nucleic Acids Res 42: 2185-2196, 2014. 